\title{
Comparative Studies on Solubility and Thermo Dynamics Properties of Natural Rubber Filled with CB/CPKS and CB/APKS Fillers
}

\author{
Malomo Dosu ${ }^{1, ~ *, ~ O l a s u p o ~ A b d u l h a k e e m ~ D a p o ", ~ O d i d i ~ D o n a l d ~ O k p o ², ~}$ \\ Adewuyi Sulaiman Olalekan ${ }^{1}$, Egharevba Owen ${ }^{2}$, Ehis-Iyoha Esohe ${ }^{2}$, Momoh Daud ${ }^{2}$, \\ Oseghale Faithful $^{2}$, Okpara Efe Godwin ${ }^{3}$, Okoh Kenneth, Sunday Felix Abimbade ${ }^{3}$ \\ ${ }^{1}$ Department of Industrial Chemistry, Federal University Oye-Ekiti, Oye-Ekiti, Ekiti, Nigeria \\ ${ }^{2}$ Rubber Research Institute of Nigeria, Benin, Nigeria \\ ${ }^{3}$ Department of Chemistry, University of Benin, Benin City, Nigeria
}

\author{
Email address: \\ dosu.malomo@fuoye.edu.ng (M. Dosu) \\ ${ }^{*}$ Corresponding author
}

To cite this article:

Malomo Dosu, Olasupo Abdulhakeem Dapo, Odidi Donald Okpo, Adewuyi Sulaiman Olalekan, Egharevba Owen, Ehis-Iyoha Esohe, Momoh Daud, Oseghale Faithful, Okpara Efe Godwin, Okoh Kenneth, Sunday Felix Abimbade. Comparative Studies on Solubility and Thermo Dynamics Properties of Natural Rubber Filled with CB/CPKS and CB/APKS Fillers. International Journal of Materials Science and Applications. Vol. 10, No. 3, 2021, pp. 46-54. doi: 10.11648/j.ijmsa.20211003.11

Received: November 19, 2020; Accepted: December 21, 2020; Published: May 14, 2021

\begin{abstract}
In this research, the comparative studies on solubility and thermodynamics properties of natural rubber vulcanizates filled with blends of activated palm kernel shell and carbonized palm kernel shell has been investigated. Palm Kernel Shell (PKS) was locally sourced. washed and sun dried to remove accompanying and moisture. The PKS was then pulverized to particle size, carbonized at $600^{\circ} \mathrm{C}$ for one hour $(1 \mathrm{hr})$ using Carbolite furnaces and chemically activated using $0.1 \mathrm{M} \mathrm{H}_{3} \mathrm{PO}_{4}$ and $0.1 \mathrm{M} \mathrm{KOH}$ solutions. The NR-filler loading concentrations of $\mathrm{CB} / \mathrm{APKS}$ and $\mathrm{CB} / \mathrm{CPKS}$ were compounded using two-roll mill. The solubility was done using three different solvents of water, kerosene and petrol respectively. The solubility results obtained for $\mathrm{CB} / \mathrm{APKS}$ and $\mathrm{CB} / \mathrm{CPKS}$ has no significance difference as the temperature varies when immersed in water. The solubility values observed for CB/APKS and CB/CPKS ranges from $1.06 \mathrm{~g}$ to $1.19 \mathrm{~g}$ and $1.03 \mathrm{~g}$ to $1.19 \mathrm{~g}$ across the samples respectively. This shows that since the filler is an organic substance, it has little or no affinity for water. In the case of kerosene and petrol, both are organics and the filler is an organic substance which follows the statement 'likedissolves-like' as the temperature increases, the absorption of kerosene is lower than that of petrol. The results recorded for kerosene across the samples of CB/APKS and CB/CPKS ranges from $1.18 \mathrm{~g}$ to $4.37 \mathrm{~g}$ and $2.02 \mathrm{~g}$ to $4.79 \mathrm{~g}$ while the results for petrol ranges from $2.25 \mathrm{~g}$ to $4.92 \mathrm{~g}$ and $2.51 \mathrm{~g}$ to $4.88 \mathrm{~g}$ respectively. This may be due to the fact that petrol is volatile and flammable compared to kerosene. The results of the activation energy were a reflection of the solvent's permeability except for water which showed contrary results. The results of the activation energy obtained for the three solvents across CB/APKS and $\mathrm{CB} / \mathrm{CPKS}$ were $5.55 \mathrm{KJ} / \mathrm{mol}$ for water, kerosene with $9.48 \mathrm{KJ} / \mathrm{mol}$ and petrol with $13.61 \mathrm{KJ} / \mathrm{mol} \mathrm{respectively}$. The results observed for water might be due to its nature as the universal solvent being entirely different from other solvents in terms of reactivity and anomalous property. This means polar solvents dissolve polar molecules while nonpolar solvents dissolve nonpolar molecules. This research shows that both $\mathrm{CB} / \mathrm{APKS}$ and $\mathrm{CB} / \mathrm{CPKS}$ possess great potential in rubber system.
\end{abstract}

Keywords: Solubility, Thermodynamics, Activation Energy, Filler, Carbonization and Chemical Activation

\section{Introduction}

Natural rubber exhibits the advantages of advanced elasticity, high strength, great toughness and manufacturing versatility. A rubber band can be stretched to 9 or 10 times its original length before returning to its original condition as 
soon as the outside pressure is released. Similarly, a block of rubber can also be compressed, and after the load is released the block will display its original shape and dimensions in a very short time. As to the extent to which it can be distorted, the rapidity of recovery and the degree to which it recovers to its original shape and dimensions, rubber is considered as unique material. Strength, toughness and elasticity are essential properties of rubber $[1,10]$. The higher strength and greater toughness of rubber provides more powerful elastic qualities in some situations where most other elastic materials may fail. Due to these properties and its dependence, rubber shows excellent resistance towards cutting, tearing and abrasion. Furthermore, this combination of useful physical properties is well maintained over a wide range of temperature from low temperatures $\left(-45^{\circ} \mathrm{C}\right)$ to relatively high temperatures $\left(120^{\circ} \mathrm{C}\right)$ which covers the most commonly used range of climatic conditions. Also, rubber is relatively inert, resistant to the deteriorating effects arising from atmosphere and many chemicals. Therefore, it has a relatively long and useful life under a wide variety of conditions. Natural rubber when vulcanized possesses unique properties such as high tensile strength, comparatively low elongation, hardness and abrasion resistance which is useful in the manufacture of various products. The main use of natural rubber is in automobile tyres. They can also be used in houses, foot wears, battery boxes, balloons, toys and so many others $[1,10]$.

The use of natural fibres as reinforcements or filler sin rubber systems has gained extra attention in recent years. Many studies have been carried out on the utilization of natural fillers such as sago, sisal, short silk fibre, oil palm, empty fruit bunch, rice husk ash, cornhub, jute fibre, rubber wood powders, hemp, kenaf and cellulosic fibres as reinforcement materials [21]. The presence of solvents in polymers upon blending may be assumed to be significant because most polymers after swelling in the solvent show reduction in their properties. The effects of these solvents are believed to be due to localized plasticization that allows the development of cracks at reduced stress [10]. Polymers for commercial applications should be chemically resistant and retain their mechanical integrity and dimensional stability on contacts with solvents [9]. Numerous literature sources have revealed excellent reports on the sorption processes as well as mechanical properties of elastomer/thermoplastic blends. Polymers swell if they interact with the solvents, and the degree of this interaction is determined by the degree of crosslink density. It has been reported that the degree of swelling can be measured or related to the thermodynamic properties of the system [11]. Considerable interest has been focused on the absorption and diffusion of organic solvents because their ability to permeate at different rate enhances the separation of component of their liquid mixture through polymeric membrane [7].

The physico-mechanical, solubility and thermodynamic studies of Natural Rubber - Neoprene Blends using variety of solvents has been studied. The results of swelling revealed that the blends with higher neoprene content showed better resistance to petrol (PMS), kerosene (DPK) and hexane compared to blends with lower neoprene contents. The order of increasing permeability of the solvents regardless of sample composition was; kerosene $>$ hexane $>$ petrol. The results of the thermodynamic studies showed that the sensitivity of reaction towards temperature as higher mass uptake values of the blends were recorded as temperature was increased in the order $30^{\circ} \mathrm{C}, 50^{\circ} \mathrm{C}$ and $70^{\circ} \mathrm{C}$. The activation energy of the swelling process was in reverse order of the permeability of the solvents. The solvent with the least permeability (petrol) had the highest activation energies in all the selected blends. [2] investigated the equilibrium sorption properties of palm kernel husk and N330 filled natural rubber vulcanizates as a function of filler volume fraction. The result obtained showed that there was a decrease in sorption with increasing filler loading which was attributed to the fact that each filler particle behaves as an obstacle to the diffusing molecules. As concentration of filler increases in the rubber matrix, more and more obstacles are created to the diffusing molecules which ultimately reduce the amount of penetrant solvent. The effect of groundnut shell filler carbonizing temperature on the mechanical properties of natural rubber composite was studied [3]. They found that the tensile strength, modulus, hardness and abrasion resistance increased with increasing filler loadings while, other properties such as compression set, flexural fatigue and elongation decreased with increasing filler loading. The percentage swelling in benzene, toluene and xylene where found to decrease with increased carbonization. [16] studied the physico mechanical effects of surface-modified sorghum stalk powder on reinforced natural rubber, and found that fillers reduces the water absorption resistance which is in agreement with Ragumathen et al, (2011). In this study, Carbonized PalmKernel Shells (CPKS) and Activated Palm Kernel Shells (APKS) were considered as reinforcing fillers in rubber. The CPKS and APKS were blended with Carbon Black (CB) and used as fillers in Natural Rubber (NR) compounding. The aim of this research is to study the solubility of CPKS and APKS filled NR vulcanizates in some common solvents as well as determine the rapidity of these processes using thermodynamic parameters

\section{Materials and Methods}

\subsection{Materials}

The equipment and apparatus used for this study include: weighing balance RS232, model WT2203GH, Saumya Two roll mill (DTRM-50) for compounding rubber, Saumya Compression moulding machine 50TONS (PID528) for vulcanization, Saumya Universal tensile machine (UTM192$2 \mathrm{~L}$ ) for testing tensile properties, Rex durometer (OS-2H) for testing hardness, Din abrasion tester (FE05000) for testing wear resistance, $250 \mathrm{ml}$ reagent bottle, Stop Watch: 31305 model, Carbolite furnace, model $\mathrm{Cw}$ 1100, Desiccator. Product number-Z553808, Oven, model DHG - 9101, Measuring cylinder: SPG1000 mL graduated, Thermometer. 
Made in Nigeria.

The materials used are Natural rubber (Ribbed Smoke Sheet), Palm Kernel Shell, Carbon black, 2, 2-Dithiobis Benzothiazole (MBTS), 1, 2-Dihydro-2, 2, 4trimethylquinoline (TMQ), zinc oxide, sulphur and stearic acid. The entire reagents are of analytical grades.

\subsection{Preparation of Agricultural Waste-derived Fillers}

\subsubsection{Carbonization}

Palm Kernel Shells (PKS) were obtained from Apomu, Osun State, Nigeria and washed to remove accompanying dirt, thereafter, sun dried for 2 days. The PKS was pulverized to particulate size, weighed and recorded. Carbonization was done using a modified method of Emmanuel et al., 2017. The dried sample was then carbonized for 1 hour at $500-600^{\circ} \mathrm{C}$ using the muffle furnace. The sample was removed from the furnace and placed in a bowl containing water for quenching and cooling. Then, the shell was drained, dried, weighed and recorded.

\subsubsection{Chemical Activation}

The palm kernel shell/carbonized palm kernel shell (CPKS/PKS) particles were activated using a modified method of Emmanuel et al., 2017. The sample was soaked in $0.1 \mathrm{MH}_{3} \mathrm{PO}_{4}$ for 24 hours. Palm kernel shell /carbonized palm kernel shell (PKS/CPKS) particles were dried in oven to obtain the initial mass recorded. The activated sample is then washed with distilled water and $0.1 \mathrm{MKOH}$ to neutralize the material being activated to $\mathrm{pH} 7$ and finally sun dried for 2-3 hours followed by oven drying for $1-2$ hours at about $170^{\circ} \mathrm{C}$. The activated/carbonized palm kernel shell particle was weighed and recorded.

\subsection{Formulation for Compounding}

The formulation used for compounding in this research is presented in Tables $1 \& 2$, measurements were carried out using part per hundred of rubber (Pphr).

Table 1. Recipe for Carbon Black/APKS Filled NR Vulcanizates.

\begin{tabular}{llllllll}
\hline SAMPLE & A & B & C & D & E & F & G \\
\hline NR & 100 & 100 & 100 & 100 & 100 & 100 & 100 \\
CB & 30 & 25 & 20 & 15 & 10 & 5 & 0 \\
APKS & 0 & 5 & 10 & 15 & 20 & 25 & 30 \\
ZnO & 4.0 & 4.0 & 4.0 & 4.0 & 4.0 & 4.0 & 4.0 \\
Sulphur & 2.0 & 2.0 & 2.0 & 2.0 & 2.0 & 2.0 & 2.0 \\
Stearic acid & 1.5 & 1.5 & 1.5 & 1.5 & 1.5 & 1.5 & 1.5 \\
MBTS & 1.5 & 1.5 & 1.5 & 1.5 & 1.5 & 1.5 & 1.5 \\
TMQ & 2.0 & 2.0 & 2.0 & 2.0 & 2.0 & 2.0 & 2.0 \\
\hline
\end{tabular}

$\mathrm{NR}=$ Natural Rubber; $\mathrm{CB}=$ Carbon black, APKS $=$ Activated Palm Kernel Shell, MBTS = 2, 2-Dithiobisbenzothiazole, TMQ =1, 2-Dihydro-2, 2, 4trimethylquinoline

Table 2. Recipe for Carbon Black/CPKS Filled NR Vulcanizates.

\begin{tabular}{|c|c|c|c|c|c|c|}
\hline SAMPLE & $\mathbf{A}$ & B & C & D & E & $\mathbf{F}$ \\
\hline NR & 100 & 100 & 100 & 100 & 100 & 100 \\
\hline CB & 25 & 20 & 15 & 10 & 5 & 0 \\
\hline CPKS & 0 & 5 & 10 & 15 & 20 & 25 \\
\hline $\mathrm{ZnO}$ & 4.0 & 4.0 & 4.0 & 4.0 & 4.0 & 4.0 \\
\hline Sulphur & 2.0 & 2.0 & 2.0 & 2.0 & 2.0 & 2.0 \\
\hline Stearic acid & 1.5 & 1.5 & 1.5 & 1.5 & 1.5 & 1.5 \\
\hline MBTS & 1.5 & 1.5 & 1.5 & 1.5 & 1.5 & 1.5 \\
\hline TMQ & 2.0 & 2.0 & 2.0 & 2.0 & 2.0 & 2.0 \\
\hline
\end{tabular}

$\mathrm{NR}=$ Natural Rubber; $\mathrm{CB}=$ Carbon black, $\mathrm{CPKS}=$ Carbonized Palm Kernel Shell

MBTS $=$ Mercaptobenzothiazoledisulphide, $\mathrm{TMQ}=1,2$-Dihydro-2, 2, 4-trimethylquinoline

\subsection{Compounding, Mastication and Mixing}

The compounding of the polymer was carried out using the two-roll-mill (DTRM-150). The mastication of the rubber was carried out first where the rubber was milled continuously to make it more elastic and soft for easy incorporation of ingredients and shaping process. The speed of the two roll mill are at ratio of 1:1.25. and the nip-setting is at $0.055-0.008$ inche at a temperature of $70^{\circ} \mathrm{C}$ and at a speed of $24 \mathrm{rpm}$.

APKS and CPKS and vulcanizates properties has been reported $[13,14]$.

\subsection{Tests}

\subsubsection{Swelling Test}

This was done to know the extent of solvent penetration in the blends. The solvents used were water, kerosene and petrol. $1.0 \mathrm{~g}$ of each sample was weighed and immersed in 20 $\mathrm{ml}$ of water for 1, 2 and 3 hours respectively. The weight of the samples was taken after each time interval. The same procedure was used for kerosene and petrol. Results were obtained in triplicates for each sample per solvent used and the average value was taken and recorded $[19,20]$. 


\subsubsection{Sorption}

All vulcanizates samples were immersed in water, kerosene and petrol at $35^{\circ} \mathrm{C}, 45^{\circ} \mathrm{C}$ and $55^{\circ} \mathrm{C}$ of temperatures for 1,2 , and 3 hours respectively and the mass uptake were taken and recorded. The percentage sorption was calculated using the relation [19].

\subsubsection{Activation Energy of the Swelling Process}

The activation energy is the minimum energy required for a reaction to proceed. In determining the activation energy of the swelling process, all samples for both $\mathrm{CB} / \mathrm{CPKS}$ and $\mathrm{CB} / \mathrm{APKS}$ were immersed in water, kerosene and petrol at $35^{\circ} \mathrm{C}, 45^{\circ} \mathrm{C}$ and $55^{\circ} \mathrm{C}$ and their mass uptake readings were taken. The natural logarithm of percentage sorption was plotted against the reciprocal of temperature for each samples and the slopes of the graphs were substituted into the Arrhenius relation; $\mathrm{K}=\mathrm{Ae} \mathrm{ea}^{\mathrm{E} / \mathrm{RT}}$ to determine the activation energy (Ea), where $\mathrm{R}$ is molar gas constant, $8.314 \mathrm{KJ} / \mathrm{mol}$ [1].

Arrhenius relation, $\mathrm{K}=\mathrm{Ae}-\mathrm{Ea} / \mathrm{RT}$

$\mathrm{Ea}=$ the activation energy,

$\mathrm{R}=$ the molar gas constant, $8.314 \mathrm{KJmol}^{-1}$

$\mathrm{T}=$ the thermodynamic temperature in Kelvin $(\mathrm{k})$

\section{Results and Discussion}

Table 3. Mass Uptakes for CB/APKS Blends at $35^{\circ} \mathrm{C}, 45^{\circ} \mathrm{C}$ and $55^{\circ} \mathrm{C}$ at Different Time Interval.

\begin{tabular}{|c|c|c|c|c|c|c|c|c|c|c|}
\hline \multicolumn{2}{|c|}{ CB/APKS Blends } & \multicolumn{3}{|c|}{ Temperature $\left(35^{\circ} \mathrm{C}\right)$} & \multicolumn{3}{|c|}{ Temperature $\left(45^{\circ} \mathrm{C}\right)$} & \multicolumn{3}{|c|}{ Temperature $\left(55^{\circ} \mathrm{C}\right)$} \\
\hline \multirow[b]{2}{*}{ Solvent } & \multirow[b]{2}{*}{ Samples } & \multicolumn{3}{|c|}{ Time (hours) } & \multicolumn{3}{|c|}{ Time (hours) } & \multicolumn{3}{|c|}{ Time (hours) } \\
\hline & & 1.0 & 2.0 & 3.0 & 1.0 & 2.0 & 3.0 & 1.0 & 2.0 & 3.0 \\
\hline \multirow{6}{*}{ Water } & 1 & 1.06 & 1.09 & 1.09 & 1.19 & 1.07 & 1.08 & 1.05 & 1.06 & 1.06 \\
\hline & 2 & 1.07 & 1.08 & 1.08 & 1.07 & 1.08 & 1.08 & 1.08 & 1.08 & 1.08 \\
\hline & 3 & 1.09 & 1.19 & 1.16 & 1.09 & 1.07 & 1.07 & 1.05 & 1.05 & 1.05 \\
\hline & 4 & 1.07 & 1.09 & 1.09 & 1.08 & 1.09 & 1.09 & 1.07 & 1.07 & 1.07 \\
\hline & 5 & 1.12 & 1.09 & 1.07 & 1.06 & 1.07 & 1.07 & 1.07 & 1.08 & 1.08 \\
\hline & 7 & 1.08 & 1.08 & 1.08 & 1.06 & 1.09 & 1.09 & 1.07 & 1.07 & 1.07 \\
\hline \multirow{7}{*}{ Kerosene } & 1 & 2.16 & 2.52 & 2.89 & 2.86 & 3.13 & 3.34 & 3.42 & 3.62 & 3.85 \\
\hline & 2 & 2.17 & 2.61 & 3.01 & 2.76 & 3.29 & 3.78 & 3.63 & 3.88 & 4.24 \\
\hline & 3 & 2.04 & 2.57 & 3.01 & 2.85 & 3.17 & 3.46 & 3.43 & 3.58 & 4.00 \\
\hline & 4 & 2.14 & 2.40 & 2.75 & 2.94 & 3.26 & 3.56 & 3.47 & 3.77 & 4.05 \\
\hline & 5 & 2.06 & 2.37 & 2.56 & 3.04 & 3.40 & 3.77 & 3.73 & 4.06 & 4.37 \\
\hline & 6 & 1.81 & 2.29 & 2.64 & 2.75 & 3.03 & 3.36 & 3.18 & 3.34 & 3.52 \\
\hline & 7 & 1.82 & 2.31 & 3.15 & 2.85 & 3.14 & 3.40 & 3.33 & 3.52 & 3.70 \\
\hline \multirow{6}{*}{ Petrol } & 2 & 2.62 & 3.70 & 4.73 & 4.20 & 3.96 & 3.81 & 2.86 & 2.71 & 2.55 \\
\hline & 3 & 2.37 & 3.51 & 4.56 & 4.00 & 3.86 & 3.72 & 3.04 & 2.83 & 2.61 \\
\hline & 4 & 2.25 & 3.19 & 4.26 & 3.31 & 3.62 & 3.57 & 2.69 & 2.65 & 2.48 \\
\hline & 5 & 2.54 & 3.53 & 4.53 & 3.18 & 2.88 & 2.77 & 2.66 & 2.57 & 2.49 \\
\hline & 6 & 2.38 & 3.49 & 4.48 & 3.05 & 3.03 & 3.03 & 2.61 & 2.54 & 2.46 \\
\hline & 7 & 2.78 & 3.88 & 4.92 & 3.36 & 3.14 & 2.94 & 2.35 & 2.34 & 2.26 \\
\hline
\end{tabular}

Kerosene (DPK = Dual Purpose Kerosene)

Petrol (PMS = Premium Motor Spirit)

\subsection{Discussion}

Solubility is the maximum amount of a substance that will dissolve in a given amount of solvent at a specific temperature. Temperature is one of the factors that affect the solubility of both solids and gases. The results for mass uptakes of $\mathrm{CB} / \mathrm{APKS}$ Blends at $35^{\circ} \mathrm{C}, 45^{\circ} \mathrm{C}$ and $55^{\circ} \mathrm{C}$ at different time intervals are presented on Table 3 . The results obtained were carried out using three different solvents which are water, kerosene and petrol respectively. It was observed that majority of the blends of $\mathrm{CB} / \mathrm{APKS}$ showed the same sorption pattern from 1 to 3 hours at $35^{\circ} \mathrm{C}, 45^{\circ} \mathrm{C}$ and $55^{\circ} \mathrm{C}$ respectively when immersed in water. The permeability of majority of the blends from sample 1 to 7 increased from 1 to 2 hours after which it either fell or remained stable after 3 hours of immersion. This trend was observed across samples 1 to 7 . The sorption values of sample 1 at $35^{\circ} \mathrm{C}$ increased from $1.06 \mathrm{~g}$ to $1.09 \mathrm{~g}$ after 2 hours, after which it remained stable at $1.09 \mathrm{~g}$ after 3 hours. At $45^{\circ} \mathrm{C}$ the sorption value decreased from $1.19 \mathrm{~g}$ to $1.07 \mathrm{~g}$ after 2 hours after which it increased to 1.08 after 3 hours. At $55^{\circ} \mathrm{C}$ the sorption values increased from $1.05 \mathrm{~g}$ to $1.06 \mathrm{~g}$ after 2 hours after which the stable value of $1.06 \mathrm{~g}$ was observed after 3 hours. Sorption values of $1.08 \mathrm{~g}$ and $1.07 \mathrm{~g}$ were recorded for sample 7 at $35^{\circ} \mathrm{C}$ and $55^{\circ} \mathrm{C}$ with the time intervals respectively while an increase sorption values from $1.06 \mathrm{~g}$ to $1.09 \mathrm{~g}$ was observed for $45^{\circ} \mathrm{C}$ after 3 hours. It was also observed that majority of the samples tend have equilibrium sorption at 2 and 3 hours at $45^{\circ} \mathrm{C}$ and $55^{\circ} \mathrm{C}$. This may be due to the permeability reaching its maximum and the blends no longer tolerating the absorption of water. After 3 hours, majority of the blends decreased as the temperature was increased, Figure 1. This was seen at sample 1 which decreased from $1.09 \mathrm{~g}$ to $1.06 \mathrm{~g}$ after $55^{\circ} \mathrm{C}$ rise. The same trend was observed for samples 3, 4 and 6 which decreased from $1.16 \mathrm{~g}$ to $1.05 \mathrm{~g}, 1.09 \mathrm{~g}$ to $1.07 \mathrm{~g}$ and $1.12 \mathrm{~g}$ to $1.08 \mathrm{~g}$ at $55^{\circ} \mathrm{C}$ respectively. A maximum sorption of $1.08 \mathrm{~g}$ was recorded for sample 2 , while an increase 
of $1.07 \mathrm{~g}$ to $1.08 \mathrm{~g}$ for sample 5 was recorded and decrease of $1.08 \mathrm{~g}$ to $1.07 \mathrm{~g}$ for sample 7 at $55^{\circ} \mathrm{C}[3,5,14,6,8]$.

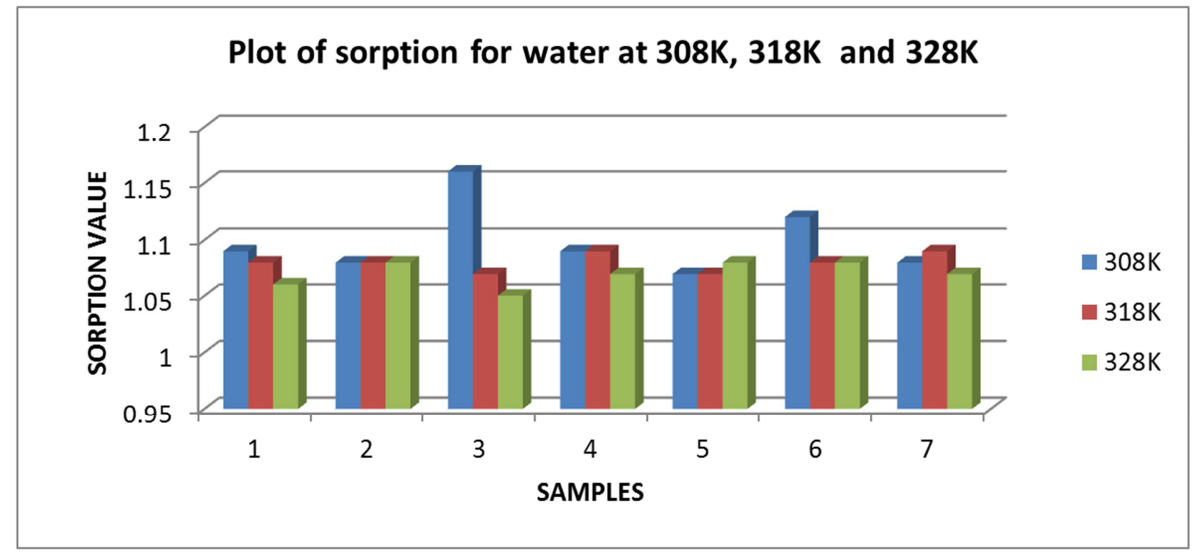

Figure 1. The graph of $C B / A P K S$ sorption for water after 3 hours at $35^{\circ} \mathrm{C}, 45^{\circ} \mathrm{C}$ and $55^{\circ} \mathrm{C}$ respectively.

For kerosene, the blends across sample 1-7 showed increase in permeability for the three temperature values of the experiment Table 3. It was observed that the sorption values increased as the time and the temperature were increased across the seven samples. Sample 1 at $35^{\circ} \mathrm{C}$ showed increase insorption value from $2.16 \mathrm{~g}$ to $2.89 \mathrm{~g}$ after 3 hours; $2.86 \mathrm{~g}$ to $3.34 \mathrm{~g}$ at $45^{\circ} \mathrm{C}$ after 3 hours and $3.42 \mathrm{~g}$ to $3.85 \mathrm{~g}$ at $55^{\circ} \mathrm{C}$ after 3 hours respectively, Figure 2. The same trend was observed across the other samples. This observation might be due to the nature of kerosene as a solvent having higher hydrocarbon content and greater compatibility, facilitating its ability to dissolve or penetrate the blends which are also having higher hydrocarbon content due to the presence of natural rubber. It could also be that the average kinetics energy of the solvent molecules was increased due to increase in temperature facilitating the solvent molecules to permeate the blends better $[12,19]$.

For petrol, an appreciable increase was observed from 1 to
3 hours at $35^{\circ} \mathrm{C}$ for all the seven samples Table 3 and Figure 3 . The sorption of sample 2 increased from $2.62 \mathrm{~g}$ to $4.73 \mathrm{~g}$ after 3 hours; sample 3 from $2.37 \mathrm{~g}$ to $4.56 \mathrm{~g}$ after 3 hours. This trend was observed across the seven samples. This observation might also be due to the non- polar nature of petrol making it to penetrate the blends which are also essentially non-polar due to the organic components. However, at $45^{\circ} \mathrm{C}$ and $55^{\circ} \mathrm{C}$ the sorption decreased from 1 to 3 hours. The sorption of sample 1 at $45^{\circ} \mathrm{C}$ decreased from $4.39 \mathrm{~g}$ to $4.21 \mathrm{~g}$ after 3 hours and also decreased at $55^{\circ} \mathrm{C}$ from $3.95 \mathrm{~g}$ to $3.71 \mathrm{~g}$ after 3 hours. The sorption also decreases in sample 7 from $3.36 \mathrm{~g}$ to $2.94 \mathrm{~g}$ and $2.35 \mathrm{~g}$ to $2.46 \mathrm{~g}$ after 3 hours for $45^{\circ} \mathrm{C}$ and $55^{\circ} \mathrm{C}$ temperature rise respectively. On the other hand, the sorption values at $45^{\circ} \mathrm{C}$ and $55^{\circ} \mathrm{C}$ were slightly greater when compared with those of $35^{\circ} \mathrm{C}$. This might be due to the effect of temperature on the permeability of the solvent arising from greater mobility of solvents or kinetic energy at elevated temperature $[5,6,13,14]$.

Table 4. Mass Uptakes for $C B / C P K S$ Blends at $35^{\circ} \mathrm{C}, 45^{\circ} \mathrm{C}$ and $55^{\circ} \mathrm{C}$ at Different Time Interval.

\begin{tabular}{|c|c|c|c|c|c|c|c|c|c|c|}
\hline \multirow{2}{*}{\multicolumn{2}{|c|}{ CB/CPKS Blends }} & \multirow{2}{*}{\multicolumn{3}{|c|}{$\begin{array}{l}\text { Temperature }\left(35^{\circ} \mathrm{C}\right) \\
\text { Time(hours) }\end{array}$}} & \multirow{2}{*}{\multicolumn{3}{|c|}{$\begin{array}{l}\text { Temperature }\left(45^{\circ} \mathrm{C}\right) \\
\text { Time(hours) }\end{array}$}} & \multirow{2}{*}{\multicolumn{3}{|c|}{$\begin{array}{l}\text { Temperature }\left(55^{\circ} \mathrm{C}\right) \\
\text { Time (hours) }\end{array}$}} \\
\hline & & & & & & & & & & \\
\hline Solvent & Samples & 1.0 & 2.0 & 3.0 & 1.0 & 2.0 & 3.0 & 1.0 & 2.0 & 3.0 \\
\hline \multirow{5}{*}{ Water } & $\mathrm{A}$ & 1.07 & 1.08 & 1.08 & 1.07 & 1.09 & 1.09 & 1.07 & 1.06 & 1.06 \\
\hline & B & 1.08 & 1.10 & 1.10 & 1.06 & 1.07 & 1.08 & 1.06 & 1.06 & 1.07 \\
\hline & $\mathrm{C}$ & 1.10 & 1.08 & 1.08 & 1.06 & 1.06 & 1.06 & 1.06 & 1.06 & 1.06 \\
\hline & $\mathrm{D}$ & 1.19 & 1.13 & 1.12 & 1.16 & 1.08 & 1.08 & 1.07 & 1.09 & 1.09 \\
\hline & $\mathrm{E}$ & 1.16 & 1.15 & 1.03 & 1.07 & 1.16 & 1.16 & 1.07 & 1.05 & 1.05 \\
\hline \multirow{7}{*}{ Kerosene } & $\mathrm{F}$ & 1.09 & 1.08 & 1.08 & 1.09 & 1.07 & 1.07 & 1.06 & 1.07 & 1.07 \\
\hline & A & 2.02 & 2.50 & 2.87 & 3.10 & 3.40 & 3.65 & 3.68 & 4.00 & 4.33 \\
\hline & B & 2.30 & 2.91 & 3.49 & 3.46 & 3.80 & 4.09 & 4.20 & 4.62 & 4.24 \\
\hline & $\mathrm{C}$ & 2.13 & 2.92 & 3.50 & 3.14 & 3.46 & 3.80 & 3.65 & 3.90 & 4.17 \\
\hline & $\mathrm{D}$ & 2.22 & 2.82 & 3.18 & 3.43 & 3.79 & 4.13 & 3.68 & 4.30 & 4.50 \\
\hline & $\mathrm{E}$ & 2.22 & 2.84 & 3.40 & 3.36 & 3.67 & 4.31 & 4.10 & 4.37 & 4.79 \\
\hline & $\mathrm{F}$ & 2.21 & 2.75 & 3.20 & 3.16 & 3.44 & 3.74 & 3.78 & 3.98 & 4.12 \\
\hline \multirow{6}{*}{ Petrol } & A & 2.51 & 3.36 & 4.38 & 3.67 & 3.04 & 3.10 & 3.15 & 3.00 & 2.85 \\
\hline & B & 2.59 & 3.86 & 4.68 & 3.89 & 3.67 & 3.51 & 3.59 & 3.42 & 2.93 \\
\hline & $\mathrm{C}$ & 2.77 & 3.89 & 4.88 & 4.22 & 3.95 & 3.84 & 3.51 & 3.36 & 3.25 \\
\hline & D & 2.76 & 3.54 & 4.63 & 4.58 & 3.14 & 3.31 & 3.10 & 3.01 & 2.95 \\
\hline & E & 2.79 & 3.72 & 4.53 & 3.97 & 3.64 & 3.49 & 3.61 & 3.18 & 3.05 \\
\hline & $\mathrm{F}$ & 2.66 & 3.74 & 4.85 & 4.24 & 3.27 & 3.07 & 3.23 & 3.10 & 3.03 \\
\hline
\end{tabular}




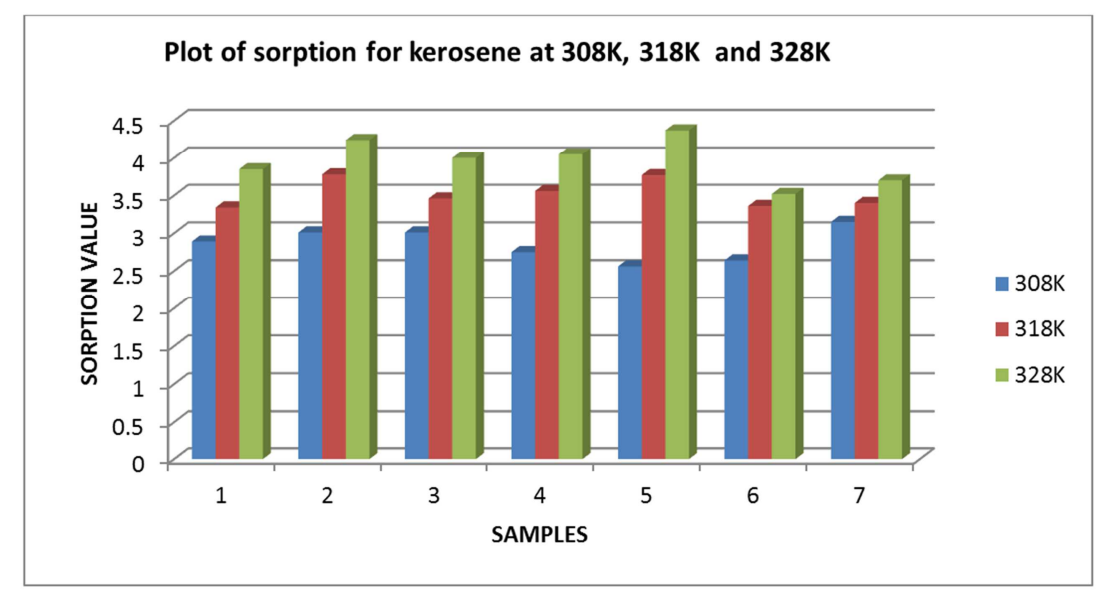

Figure 2. The graph of $C B / A P K S$ sorption for kerosene after 3 hours at $35^{\circ} \mathrm{C}, 45^{\circ} \mathrm{C}$ and $55^{\circ} \mathrm{C}$ respectively.

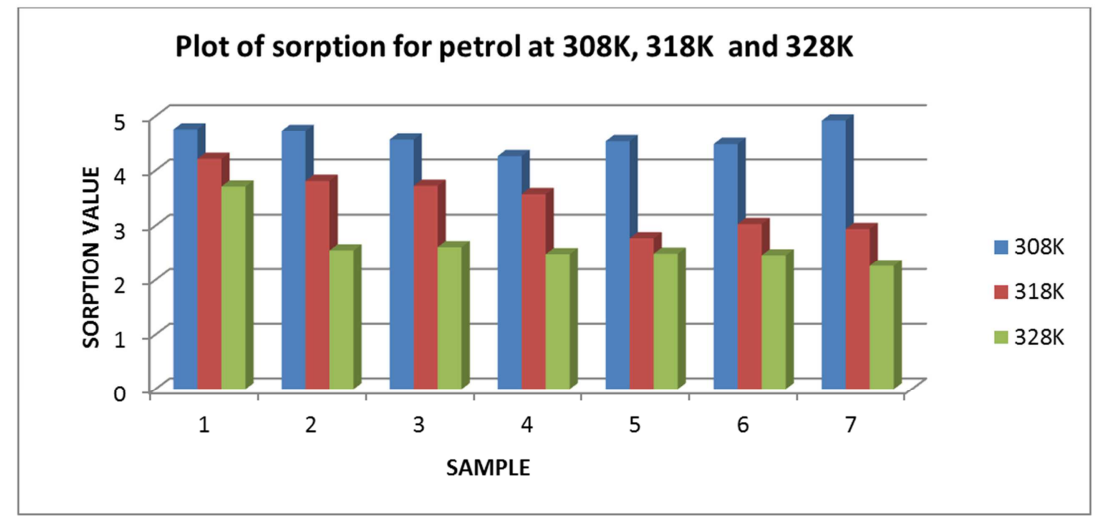

Figure 3. The graph of CB/APKS sorption for petrol after 3 hours at $35^{\circ} \mathrm{C}, 45^{\circ} \mathrm{C}$ and $55^{\circ} \mathrm{C}$ respectively.

The results for mass uptakes by $\mathrm{CB} / \mathrm{CPKS}$ Blends at $35^{\circ} \mathrm{C}$, $45^{\circ} \mathrm{C}$ and $55^{\circ} \mathrm{C}$ at different time intervals are presented on Table 4. The results obtained were also carried out using three different solvents, which are water, kerosene and petrol [15].

The sorption for majority of the blends immersed in water at $35^{\circ} \mathrm{C}$ tends to increase as the CPKS values and $\mathrm{CB}$ values increased and decreased respectively. The sorption as the CPKS content increased from sample A to D was found to increase from $1.07 \mathrm{~g}$ to $1.19 \mathrm{~g}$. A decrease was only observed at higher CPKS composition and this might be due to the lower content of $\mathrm{CB}$ in the blends suggesting that higher $\mathrm{CB}$ loading might possess better reinforcing and strength impacting properties than CPKS. However, the sorption values of most of the blends either decreased from 1 to 3 hours or remain stable after an observable increase or decrease. This might also be because the blends no longer have capacity for absorption of the solvent making the sorption to be at maximum. At $45^{\circ} \mathrm{C}$ and $55^{\circ} \mathrm{C}$ most blends across sample A to $\mathrm{F}$ showed a stable sorption values after 3 hours indicating the reduction in absorption capacity of the blends, Figure $4(18,19)$.

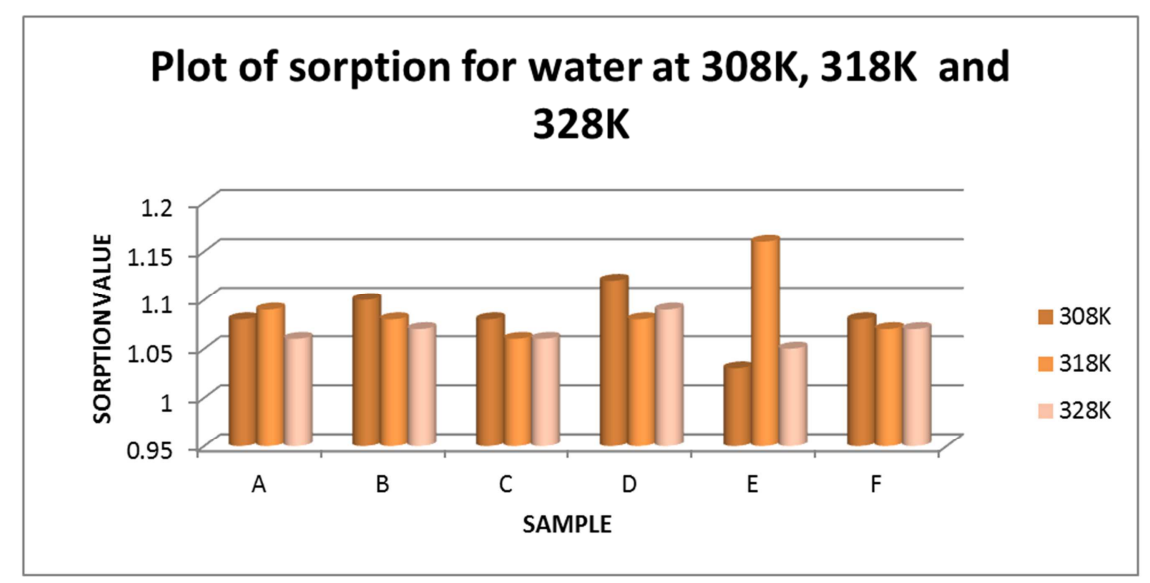

Figure 4. The graph of $C B / C P K S$ sorption for water after 3 hours at $35^{\circ} \mathrm{C}, 45^{\circ} \mathrm{C}$ and $55^{\circ} \mathrm{C}$ respectively. 
The sorption values across sample A to $\mathrm{F}$ increased from 1 to 3 hours when the samples were immersed in kerosene Table 4 and Figure 5 respectively. Sample A at $35^{\circ} \mathrm{C}$ increased from $2.02 \mathrm{~g}$ to $2.87 \mathrm{~g}$ after 3 hours; sample $\mathrm{C}$ from $2.30 \mathrm{~g}$ to $3.49 \mathrm{~g}$ after 3 hours; sample F from $2.21 \mathrm{~g}$ to $3.20 \mathrm{~g}$ after 3 hours. The same trend was observed at $45^{\circ} \mathrm{C}$ and $55^{\circ} \mathrm{C}$ for most of the blends. This observation may be as a result of nonpolar solvents dissolving non polar molecules. Therefore, kerosene being a nonpolar solvent facilitates its penetrating power to penetrate the blends $[17,18]$.

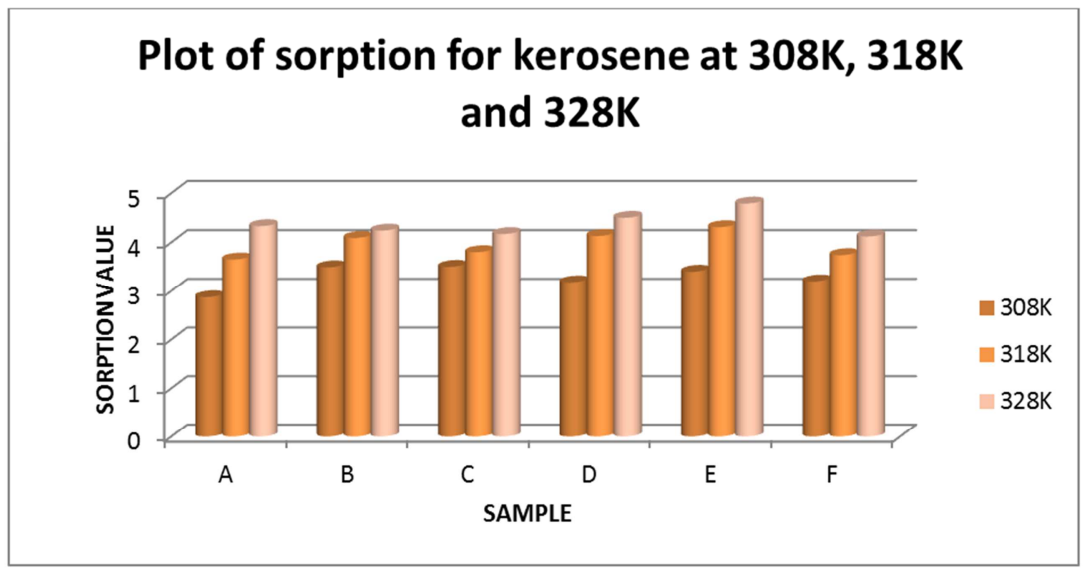

Figure 5. The graph of $C B / C P K S$ sorption for kerosene after 3 hours at $35^{\circ} \mathrm{C}, 45^{\circ} \mathrm{C}$ and $55^{\circ} \mathrm{C}$ respectively.

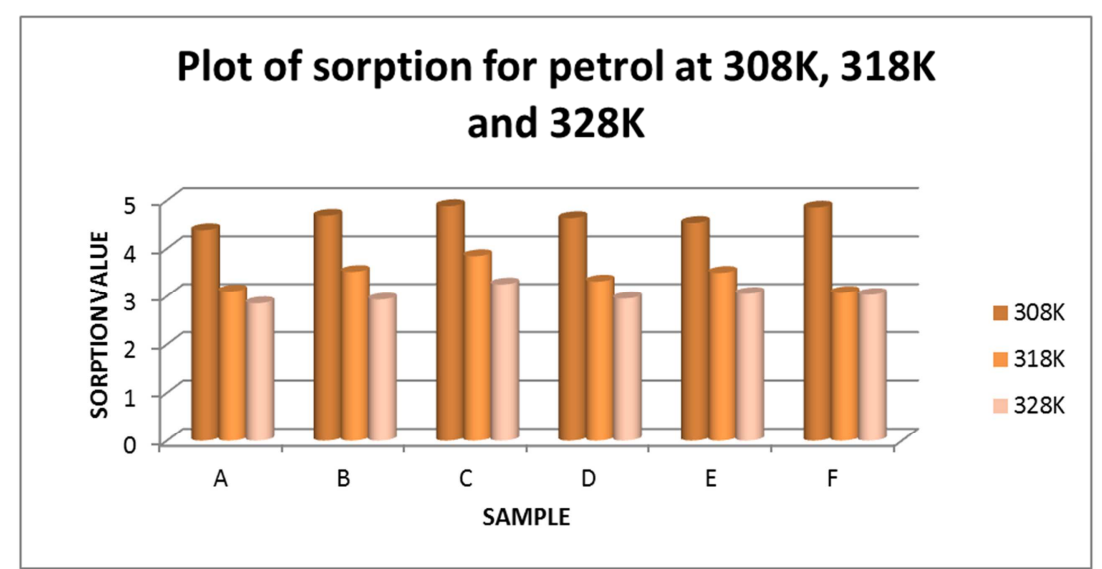

Figure 6. The graph of $C B / C P K S$ sorption for petrol after 3 hours at $35^{\circ} \mathrm{C}, 45^{\circ} \mathrm{C}$ and $55^{\circ} \mathrm{C}$ respectively.

The sorption of the samples at $35^{\circ} \mathrm{C}$ when immersed in petrol showed an appreciable increase from 1 to 3 hours, Table 4 and Figure 6. This trend was observed for all the blends for example the sorption of sample A increased from $2.51 \mathrm{~g}$ to $4.38 \mathrm{~g}$ after 3 hours; sample D $2.79 \mathrm{~g}$ to $4.53 \mathrm{~g}$ after 3 hours; sample F $2.66 \mathrm{~g}$ to $4.85 \mathrm{~g}$ after 3 hours respectively. This observation may be as a result of non-polar solvents dissolving non-polar molecules. However, the sorption for most blends decreased from 1 to 3 hours at $45^{\circ} \mathrm{C}$ and $55^{\circ} \mathrm{C}$. The sorption of sample A decreased from $3.67 \mathrm{~g}$ to $3.10 \mathrm{~g}$ at $45^{\circ} \mathrm{C}$ and $3.15 \mathrm{~g}$ to $2.85 \mathrm{~g}$ at $55^{\circ} \mathrm{C}$ after 3 hours; sample $\mathrm{C}$ from $4.22 \mathrm{~g}$ to $3.84 \mathrm{~g}$ at and $3.51 \mathrm{~g}$ to $3.25 \mathrm{~g}$ at $55^{\circ} \mathrm{C}$ after 3 hours; sample $\mathrm{F} 4.24 \mathrm{~g}$ to $3.07 \mathrm{~g}$ at $45^{\circ} \mathrm{C}$ and $3.23 \mathrm{~g}$ to $3.03 \mathrm{~g}$ at $55^{\circ} \mathrm{C}$ after 3 hours respectively. This observation could be due to the effect of temperature on the permeability of the solvent because at a given temperature the activation energy depends on the nature of the chemical transformation that takes place but not on the relative energy state of the reactants and products $[8,9]$.
Therefore, the solubility of $\mathrm{CB} / \mathrm{APKS}$ had no significant difference as the temperature is varied. This shows that since the filler is an organic substance, it has little or no affinity for water with highest absorption of $1.16 \mathrm{~g}$ after 3 hours (sample 3 ). In the case of kerosene and petrol, both are organic solvents and the filler is an organic substance which follows the statement that 'like-dissolves-like'. As the temperature increases, the absorption of kerosene is lower than that of petrol. This is evident that petrol is more volatile and flammable compared to kerosene as both are non-polar solvents $[1,2,5,8,18]$.

In the case of $\mathrm{CB} / \mathrm{CPKS}$, there is no significant solubility in water, but petrol was absorbed better than kerosene which, may be due to its volatility and flammability. Also, increase in temperature allows the filler particles to become more mobile due to increase in kinetic energy which make the solvent molecules to interact more with the filler particles as observed in petrol and kerosene. Therefore the low solubility of the fillers in the different solvents may be due to low 
reaction surface of the filled vulcanizates using bio fillers used $[15,17,18]$. Also, the level of cross-link to filler dispersion, nature of solvent and type of fillers used are being considered $[13,5,9]$.

Generally, petrol being a mixture of hydrocarbons with a lower molecular weight than Kerosene may be expected to diffuse faster and be accommodated in the rubber matrix with fewer hindrances. The decrease in sorption with increasing filler loading may arise from filler particles behaving as an obstacle to the diffusing molecule. As filter loading increase in rubber matrix, more and more obstacles are created to the diffusing molecule and thus reduce the amount of penetrated solvent. $[1,8,10]$ explain why higher sorption values were obtained for low molecular weight hydrocarbons.

Table 5. Activation energy of water, kerosene and petrol for all samples of $C B / C P K S$ after 3 hours.

\begin{tabular}{|c|c|c|c|}
\hline \multirow{2}{*}{$\begin{array}{l}\text { CB/CPKS } \\
\text { Samples } \\
\end{array}$} & \multicolumn{3}{|c|}{ Solvents with the Activation Energy $(\mathrm{KJ} / \mathrm{mol})$} \\
\hline & Water & Kerosene & Petrol \\
\hline A $25 / 0$ & 11.96 & 23.99 & 25.06 \\
\hline B $20 / 5$ & 14.83 & 43.22 & 26.83 \\
\hline $\mathrm{C} 15 / 10$ & 11.96 & 9.88 & 22.63 \\
\hline D $10 / 15$ & 11.97 & 19.68 & 25.83 \\
\hline E $5 / 20$ & 21.24 & 18.99 & 22.59 \\
\hline $\mathrm{F} 025$ & 5.55 & 14.53 & 26.61 \\
\hline
\end{tabular}

Table 6. Activation energy of water, kerosene and petrol for all samples of $C B / A P K S$ after 3hours.

\begin{tabular}{llll}
\hline CB/APKS & \multicolumn{3}{l}{ Solvents with the Activation Energy $(\mathbf{K J} / \mathbf{m o l})$} \\
\cline { 2 - 4 } Samples & Water & Kerosene & Petrol \\
\hline $130 / 0$ & 16.85 & 17.07 & 13.61 \\
$225 / 5$ & $1 . .15 \times 10^{-12}$ & 19.86 & 36.51 \\
$320 / 10$ & 48.36 & 16.65 & 32.99 \\
$415 / 15$ & 10.44 & 23.10 & 32.83 \\
$510 / 20$ & 5.55 & 32.02 & 35.86 \\
$65 / 25$ & 16.86 & 17.86 & 36.11 \\
$70 / 30$ & 5.55 & 9.48 & 47.18 \\
\hline
\end{tabular}

\subsection{Activation Energy}

The activation energy being the minimum energy required for a chemical reaction to occur, connotes the lesser the activation energy the easier it is for the reactant particles to overcome the energy barrier and form product and vice versa. In this context, the permeability of the solvent is inversely proportional to the activation energy for most blends i.e the better the solvent permeates the blends, the lesser the activation energy and vice versa. For sample A-F, the solvent that the blends most was kerosene, followed by petrol and water. The results of the activation energy were a reflection of the solvent's permeability except for water which showed a different pattern. The results observed for water might be due to its polar nature solvent and wide differences in solubility parameters with the majority of the ingredients in the vulcanizates. The activation energy of sample A for kerosene, petrol and water were $23.99 \mathrm{KJ} / \mathrm{mol}, 25.06 \mathrm{KJ} / \mathrm{mol}$ and $11.96 \mathrm{KJ} / \mathrm{mol}$; Sample C; $9.88 \mathrm{KJ} / \mathrm{mol}, 22.63 \mathrm{KJ} / \mathrm{mol}$ and $11.96 \mathrm{KJ} / \mathrm{mol}$; Sample F; $14.53 \mathrm{KJ} / \mathrm{mol}, 26.61 \mathrm{KJ} / \mathrm{mol}$ and
$5.55 \mathrm{KJ} / \mathrm{mol}$ respectively, Table 5 . The permeability in kerosene and petrol is as results nonpolar solventsto dissolve nonpolar molecules $[1,2,4,8,10,14,18]$.

Similar explanation can be given for sample 1-7, Table 6 . The activation energy for kerosene, petrol and water were $17.07 \mathrm{KJ} / \mathrm{mol}, 13.61 \mathrm{KJ} / \mathrm{mol}$ and $16.85 \mathrm{KJ} / \mathrm{mol}$ for sample 1 respectively with petrol being the solvent that permeated the blend most for sample 1. The activation energy for kerosene, petrol and water for sample 4 were $23.10 \mathrm{KJ} / \mathrm{mol}$, $32.83 \mathrm{KJ} / \mathrm{mol}$ and $10.44 \mathrm{KJ} / \mathrm{mol}$ respectively with kerosene having highest activation energy. The results recorded for sample 7 were $9.48 \mathrm{KJ} / \mathrm{mol} 47.18 \mathrm{KJ} / \mathrm{mol}$ and $5.55 \mathrm{KJ} / \mathrm{mol}$ for kerosene, petrol and water respectively. The same trend was observed for sample 5. The results of activation energy of both the $\mathrm{CB} / \mathrm{APKS}$ and $\mathrm{CB} / \mathrm{CPKS}$ may be due to the aggregation of carbon chain in the organic compounds as a results of the increase in the fillers which reduces ignition and bring about increase in modulus and tensile strength [4] which make the reactions in petrol and kerosene with samples variation difficult $[1,2,4,8,10,14,18]$.

\section{Conclusion}

The solubility and thermodynamics studies of $\mathrm{CB} / \mathrm{APKS}$ and $\mathrm{CB} / \mathrm{CPKS}$ filled NRblends were investigated. The study showed that blend loading composition and the nature of the organic molecule played a significant role in determining the mass uptake. This shows that since the filler is an organic substance, it has little or no affinity for water. In the case of kerosene and petrol, both are organics and the filler is an organic substance which follows the statement 'likedissolved-like'. As the temperature increases, the absorption of kerosene is lower than that of petrol. The results of the activation energy were a reflection of the solvent's permeability except for water which showed contrary results. The results observed for water might be due to its nature as the universal solvent being entirely different from other solvents in terms of reactivity and anomalous property. This means polar solvents dissolve polar molecules while nonpolar solvents dissolve nonpolar molecules. This research shows that both $\mathrm{CB} / \mathrm{APKS}$ and $\mathrm{CB} / \mathrm{CPKS}$ possess great potential in rubber science and technology.

\section{References}

[1] Atkins, P. W. (1978). Physical Chemistry. 1st edition. Oxford University Press. Pp 864-865.

[2] Akporhonor E. E, Egwaihide P. A. and Okieimen F. E. (2007). Equilibrium Sorption Properties of Palm Kernel Husk and N330 Filled Natural Rubber Vulcanizate as a Function of Filler Volume Fraction, Scientific research and essay, 2 (5), 159-162.

[3] Ayo M. D., Madufor I. C. and Ekebafe L. O. (2011). Effect of Groundnut Shell Filler Carbonizing Temperature on the Mechanical Properties of Natural Rubber Composite. Pacific Journal of Science and Technology, 21 (1), 55-58. 
[4] Ekebafe, L. O., Imanah, J. E. and Okieimen, F. E. (2010). Physico-mechanical properties of rubber seed shell carbonfilled natural rubber, Benin City, Nigeria. Chemical Industry \& Chemical Engineering Quarterly scientific journal, 16 (2) $149-156$.

[5] Egwaikhide, P. A. Akporhonor, E. E. and Okieimen, F. E. (2007). Effect of coconut fibre filler on the cure characteristics physico-mechanical and swelling properties of natural rubber vulcanisates, University of Benin City, Nigeria. International Journal of Physical Sciences Vol. 2 (2), 039-046.

[6] Emmanuel O., Sangotayo, Itabiyi, Olukunle E., Adedeji, Kasali A., Adegoke, Tona, Elehinafe and Oluwatosin L. (2017). Characterization of Activated Carbon Produced from Agricultural Residue. Journal of Scientific and Engineering Research, 4 (6): 132-140.

[7] Frollini A. E., Leao L. H. C. and Matt O. S. O. (2002). Natural Polymers and Agro-fibers Composite, San Carlos, Brazil, 1st edition, 1-6.

[8] Gent N. and Lui G. L. (1991). Swelling and electrical properties of rubber vulcanizates loaded with paraffin wax. Journal of Polymer Science Polymer Physics, 29: 1313-1319.

[9] Henry C. O., Okoro O. and Igwe I. O. (2009). Diffusion Characteristics of Toluene into Natural Rubber/LLDPE Blends, International Journal of polymer science, 20, 1-6.

[10] Jeol R. F. (2005). Polymer Science and Technology, New Delhi: Prentice-Hall, Second edition, 359.

[11] Iannace S. Ali, and Nicolaise L. E. (2001). Processing Conditions on Dimensions of Sisal Bers in Thermoplastic Biodegradable Composites, Journal of Applied Polymer Science, 79 (6), 108491.

[12] Letcher, Trevor. (2007). Thermodynamics, solubility and environmental issues. $1^{\text {st }}$ edition. Amsterdam: Elsevierscience.

[13] Malomo D., Olasupo A. D., Adesigbin A. M., Egharevba O.,
Adewuyi S. O. Odubunmi J. O., Idemudia L., Abimbade S. F. and Ogunyemi E. K. (2020). Comparative Studies on the Physico-Mechanical Properties of Natural Rubber Filled with $\mathrm{CB} / \mathrm{CPKS}$ and CB/APKS Vulcanizates, J. Chem. Bio. Phy. Sci. 10,$3 ; 211-226$.

[14] Malomo, D., Adesigbin, M. A., Egharevba, O., Bello, A., Adewuyi, S. O. and Idemudia, L. (2019). Physico-Mechanical, Solubility and Thermodynamic Studies of Natural Rubber Neoprene Blends. J. Chem Soc. Nigeria, 44, 4, pp 718-725.

[15] Ogbeifun, D. E., Iyasele, J. U. and Okieimen, F. E. (2010). Physico-mechanical Properties of natural rubber vulcanizates filled with carbonized agricultural residues, department of chemistry, University of Benin, Benin City, Nigeria. Journal of naturalsciences, engineering and technology, ISSN - 2277 -0593 .

[16] Yakubu M. K., Gumel M. S., Umar A. and Metelerkamp R. (2010). Physic -Mechanical Effects of Surface Modified Sorgum Stalk Powder On Reinforced Natural Rubber, Journal of reinforced plastic and composites, 29 (18), 50-63.

[17] Yalkowsky, Samuel H. (1999). Solubility and solubilization in aqueous media, $1^{\text {st }}$ edition. Washington D.C, American chemical.

[18] Ragunathan S, Hanafi I and Kamarudin H. (2011). Mechanical properties, water absorption and swelling behaviour of Rice Husk powder filled PP/RHP using silane as coupling agnt, Bioresources, 6, 70-78.

[19] Rania, M. M. (2011). Properties of rubber blends based on natural rubber loaded with Different fillers and cured by gamma radiation. Pp 17-18; 55.

[20] Roslim, R; Amir, M. Y and Aguro, P. T. (2012). Natural latex form. 8: 15-27.

[21] Satyanarayana K. G, Arizaga G. G. C. and Wypych F. (2009). Biodegradable Composites Based on LignocellulosicFibres: An Overview, Progress in Polymer Science, 34, 982-1. 